\title{
The relevance of magnesium homeostasis in COVID-19
}

\author{
Valentina Trapani ${ }^{1,2}$ (1) $\cdot$ Andrea Rosanoff $^{3} \cdot$ Shadi Baniasadi $^{4} \cdot$ Mario Barbagallo $^{5} \cdot$ Sara Castiglioni ${ }^{6}$. \\ Fernando Guerrero-Romero ${ }^{7} \cdot$ Stefano lotti $^{8} \cdot$ André Mazur $^{9} \cdot$ Oliver Micke $^{10} \cdot$ Guitti Pourdowlat $^{11}$. \\ Giuliana Scarpati ${ }^{12} \cdot$ Federica I. Wolf $^{1} \cdot$ Jeanette A. Maier ${ }^{6}$
}

Received: 21 June 2021 / Accepted: 6 October 2021 / Published online: 23 October 2021

(c) The Author(s) 2021

\begin{abstract}
Purpose In less than one and a half year, the COVID-19 pandemic has nearly brought to a collapse our health care and economic systems. The scientific research community has concentrated all possible efforts to understand the pathogenesis of this complex disease, and several groups have recently emphasized recommendations for nutritional support in COVID-19 patients. In this scoping review, we aim at encouraging a deeper appreciation of magnesium in clinical nutrition, in view of the vital role of magnesium and the numerous links between the pathophysiology of SARS-CoV-2 infection and magnesiumdependent functions.

Methods By searching PubMed and Google Scholar from 1990 to date, we review existing evidence from experimental and clinical studies on the role of magnesium in chronic non-communicable diseases and infectious diseases, and we focus on recent reports of alterations of magnesium homeostasis in COVID-19 patients and their association with disease outcomes. Importantly, we conduct a census on ongoing clinical trials specifically dedicated to disclosing the role of magnesium in COVID-19.

Results Despite many methodological limitations, existing data seem to corroborate an association between deranged magnesium homeostasis and COVID-19, and call for further and better studies to explore the prophylactic or therapeutic potential of magnesium supplementation.

Conclusion We propose to reconsider the relevance of magnesium, frequently overlooked in clinical practice. Therefore, magnesemia should be monitored and, in case of imbalanced magnesium homeostasis, an appropriate nutritional regimen or supplementation might contribute to protect against SARS-CoV-2 infection, reduce severity of COVID-19 symptoms and facilitate the recovery after the acute phase.
\end{abstract}

Keywords Aging $\cdot$ Chronic non-communicable diseases $\cdot$ Immune response $\cdot$ Long COVID $\cdot$ Magnesemia $\cdot$ SARS-CoV-2

Federica I. Wolf

federica.wolf@unicatt.it

$\triangle$ Jeanette A. Maier

jeanette.maier@unimi.it

1 Sezione di Patologia Generale, Dipartimento di Medicina e Chirurgia Traslazionale, Fondazione Policlinico Universitario A. Gemelli IRCCS-Università Cattolica del Sacro Cuore, Largo F. Vito 1, 00168 Rome, Italy

2 Alleanza Contro Il Cancro, Rome, Italy

3 CMER Center for Magnesium Education and Research, Pahoa, Hawaii, USA

4 Tracheal Diseases Research Center, National Research Institute of Tuberculosis and Lung Diseases (NRITLD), Shahid Beheshti University of Medical Sciences, Tehran, Islamic Republic of Iran

5 Geriatric Unit, Department of Medicine, University of Palermo, Palermo, Italy
6 Dipartimento di Scienze Biomediche e Cliniche L. Sacco, Università di Milano, Via G.B. Grassi 74, 20157 Milan, Italy

7 Biomedical Research Unit of Mexican Social Security Institute, Durango, Mexico

8 Department of Pharmacy and Biotechnology (FaBit) National Institute of Biostructures and Biosystems, Università di Bologna, Bologna, Italy

9 Unité de Nutrition Humaine, INRAE, UNH, Université Clermont Auvergne, Clermont-Ferrand, France

10 Department of Radiotherapy and Radiation Oncology, Franziskus Hospital, Bielefeld, Germany

11 Chronic Respiratory Diseases Research Center, National Research Institute of Tuberculosis and Lung Diseases (NRITLD), Shahid Beheshti University of Medical Sciences, Tehran, Islamic Republic of Iran

12 Anestesiologia e Rianimazione, Dipartimento di Medicina e Chirurgia, Università Degli Studi di Salerno, Fisciano, Italy 


\section{Introduction}

As of June 18, 2021, more than 176 million cumulative confirmed COVID-19 cases have been reported, claiming more than 3.5 million lives all over the world [1], and the numbers are still growing. At an unprecedented speed, vaccines were developed and approved for immunization [2]. Although about 2,310,000,000 vaccines have been administered, we are far from the eradication of the disease. In addition, evidence is accumulating about the lingering effects experienced by recovered COVID-19 patients, even after a mild to moderate disease [3]. While scientists are searching for a specific therapy to treat the disease, there is an urgent need to individuate strategies to reinforce the immune system and prevent the infection, to mitigate the progression of the disease, and to ameliorate symptoms of long COVID. A balanced diet is essential to strengthen immune responses and to harmonize the microbiota, a complex ecosystem important for health [4]. The nutritional status of the patient influences the course of COVID-19, however knowledge about the nutritional support of COVID patients is very limited [5].

When the current SARS-CoV-2 pandemic began in early 2020, the global magnesium researcher group (MaGNet [6]) was alerted by the striking similarities between COVID-19 risk factors and conditions linked to magnesium deficit state in humans [7-9] such as age, diabetes, obesity, high blood pressure, arrhythmias, thrombosis and cardiovascular diseases. These conditions, which are associated with high odds of COVID-19 mortality [10, 11], are common in Western Societies and spreading globally. Indeed, food processing losses resulting in lower dietary magnesium intakes, reduced magnesium availability in the soil and, therefore, in the food chain, long-term prescribed drugs such as proton pump inhibitors, all might precipitate subclinical magnesium deficiency [12].

Moreover, we reasoned that magnesium deficiency might play a role in the pathophysiology of COVID-19. Even if the respiratory track is the primary site of the disease, the virus can disseminate to other tissues and complicate the clinical picture, eventually culminating in multi-organ failure [13]. Key mechanisms implicated in the disease include direct viral cytotoxicity, endothelial dysfunction and exaggerated release of inflammatory cytokines. Very early after the outbreak of the pandemic, it became evident that endotheliopathy is present in COVID19 and is likely to be associated with critical illness and death, to the point that evaluation of endothelial markers is recommended and, in parallel, therapies are sought to preserve endothelial function $[14,15]$. Notably, low magnesium induces a pro-inflammatory, pro-thrombotic phenotype in endothelial cells [16] and promotes platelet aggregation, release of beta-thromboglobulin and thromboxanes, all events that favor the development of thromboembolism [17]. Endothelial injury and hypercoagulable state are key components of the Virchow's triad and might explain the high incidence of thromboembolic events in COVID-19 patients. Moreover, magnesium deficits may exacerbate the inflammatory response induced by SARSCoV-2, maintaining and propagating the so-called cytokine storm, a reaction that leads to acute respiratory distress syndrome (ARDS), accentuates endothelial dysfunction and coagulopathy, and promotes multiple organ failure. In addition, other symptoms reported by COVID-19 patients, such as asthenia, myalgias, anxiety, depression, insomnia, might be attributable to magnesium deficiency [7].

PubMed and Google Scholar were used to pinpoint studies and articles on the topic of interest. Journal articles published between 1990 and June 2021 were reviewed. Keywords included "magnesium", "Sars-CoV-2", "COVID-19", "long COVID", "diabetes", "obesity", "aging”, "infectious diseases", "hypertension", "atherosclerosis", "hypomagnesemia", "thrombosis". We selected only papers written in English and covering in vitro, animal and human studies.

On these bases, we discuss the physiological role of magnesium, the link between magnesium deficiency and chronic non-communicable diseases which represent a risk factor for severe COVID-19, the potential contribution of a low magnesium status to the pathogenesis of the disease to conclude with a rapid overview of clinical studies available in the literature and a summary of ongoing research on the topic.

\section{Magnesium, a metabolite}

The role of magnesium in cell and tissue metabolism is complex and multifactorial. Accumulating evidence suggests that magnesium acts primarily as a key signaling element and metabolite in cell physiology. Consequently, the concept that magnesium is an electrolyte is too simplistic and obsolete [18-22]. Magnesium is involved in all metabolic and biochemical pathways and is required in a wide range of vital functions, such as bone formation, neuromuscular activity, signaling pathways, bioenergetics, glucose, lipid and protein metabolism, DNA and RNA stability, and cell proliferation. The enzymatic databases list more than 600 enzymes with magnesium indicated as cofactor, and additional 200 are reported in which magnesium acts as an activator [23]. However, it should be specified that, since it interacts directly with the substrate, magnesium is itself a substrate rather than a cofactor [20, 24]. Indeed, since $\mathrm{Mg}^{2+}$ binds to the phosphate moieties of metabolites, the phosphorylated molecules (i.e., ATP, phosphocreatine, as well as all the other phosphometabolites including those related to carbohydrate metabolism and cellular bioenergetics) form a complex 
with magnesium. This implies that the actual substrates of the biochemical reactions involving these metabolites are magnesium complexes. This is the reason why magnesium should be regarded as a metabolite and not as a cofactor acting in ancillary fashion in biochemical reactions [20]. As a paradigmatic example, the binding between ATP and $\mathrm{Mg}^{2+}$ results in an adequate conformation that allows to weaken the terminal O-P bond of ATP, thereby facilitating the transfer of phosphate [23]. Hence, the "active species" is not ATP, but $\mathrm{MgATP}^{2-}$ [20]. This concept is further sustained by the fact that, differently from other ions for which cells maintain transmembrane gradients, intra- and extracellular free magnesium $\left(\mathrm{Mg}^{2+}\right)$ concentrations are comparable [24]. The total (bound + free) intracellular magnesium concentrations range from 10 to $30 \mathrm{mM}$. However, since most magnesium is bound to polynucleotides, ATP, phosphorylated metabolites and proteins, the concentration of its intracellular ionic (free) form falls in the range of $0.5-1.2 \mathrm{mM}$ [25]. The little amount of intracellular $\left[\mathrm{Mg}^{2+}\right]$, as compared to the intracellular $\left[\mathrm{Na}^{+}\right]$and $\left[\mathrm{K}^{+}\right]$, which are in the order of 50 and $150 \mathrm{mM}$ respectively [20], strengthens the evidence that the contribution of magnesium to the electric charge of the cell is almost negligible. Therefore, it is time to revise the concept that magnesium is an electrolyte.

The total body magnesium of an adult is approximately $25 \mathrm{~g}$, of which $50-60 \%$ is in bone, and the remaining $40 \%-50 \%$ is in the soft tissues, with less than $1 \%$ present in the blood [25]. Magnesium is mostly absorbed by the small intestine and to lesser extent by the large intestine, and excreted by kidney through the finely tuned activity of many $\mathrm{Mg}^{2+}$ transporters [26].

Serum magnesium concentration in blood can be efficiently buffered by renal excretion and, in part, by its release from bones. In addition, magnesium is an intracellular cation whose content depends on the tissue and its metabolic state [27, 28]. Therefore, serum magnesium values within the reference range may not rule out a systemic magnesium-depleted state, and the clinical impact of magnesium deficiency may be easily underestimated [27-29]. Nevertheless, in the absence of a satisfactory and easily measurable biomarker to assess magnesium state, we have to rely on serum magnesium levels, which are found to be altered in many diseases.

Unfortunately, serum magnesium levels are still not determined routinely in daily clinical practice. Worldwide, they are measured primarily in critically ill subjects and sometimes in elderly people at hospital admission. In view of the large variety of pathophysiological conditions associated to a decrease of magnesium availability, we strongly suggest to include magnesium in the evaluation of the blood ionogram.
Magnesium deficit in aging and non-communicable chronic diseases

The overall prevalence of hypomagnesemia in geriatric patients reaches $36 \%$ [30], among diabetic patients ranges from $19 \%$ to $29 \%$ [31, 32], and in patients with high blood pressure, it has been found to be $63.8 \%$ [33]. In addition, it has been reported that magnesium deficiency is associated with obesity and the increased incidence of hypertension, cardiovascular disease, congestive heart failure, arrhythmias, and chronic kidney disease, particularly in patients under dialysis [34-36]. Furthermore, it has been noted that mortality by cardiovascular deaths in subjects with hypomagnesemia is significantly higher as compared with individuals exhibiting normal magnesium levels [37]. Within this context, hypomagnesemia, at the time of admission in the Intensive Care Unit (ICU), is associated with the length of stay, need for mechanical ventilation, and mortality [38].

Because patients with diabetes, particularly the elderly with type 2 diabetes (T2DM), are at a higher risk of severe disease or death due to SARS-CoV-2 infection than agematched individuals without diabetes, it is of interest to recall that a consistent body of evidence has linked magnesium deficiency to alterations of insulin sensitivity, including metabolic syndrome and T2DM [39]. Indeed, T2DM has been associated with several magnesium abnormalities [40, 41]. An umbrella review to map and grade health outcomes linking to magnesium intake and supplementation confirmed that an elevated magnesium intake is associated with a decreased risk of T2DM [42].

Finally, it is important to highlight that magnesium modulates the contractile state of bronchial smooth muscle cells. Hypomagnesemia increases airway reactivity susceptibility to recurrent upper respiratory tract infections, and development of pulmonary fibrosis [7, 43]. Magnesium depletion triggers bronchial contraction and spasm, while magnesium supplementation produces bronchial relaxation [40, 44]. Several possible mechanisms have been postulated for the positive magnesium action to relax bronchial smooth muscle, such as its calcium channel blocking action, a decreased sensibility to the depolarizing action of acetylcholine, a stabilization of mast cells and T lymphocytes, and a stimulation of nitric oxide and prostacyclin release [40]. Accordingly, nebulized magnesium sulfate has been used as a bronchodilator agent in adjuvant care of asthmatic patients [45]. Moreover, because of its vasodilatory, anti-inflammatory and antithrombotic effects, magnesium may reduce the respiratory symptoms and improve lung function of COVID-19 patients. All these effects might contribute to the reduction of the ventilation-perfusion mismatch, which is one of the most important reasons for hypoxemia in COVID-19 patients, and to the improvement of oxygenation in these patients [46]. Additionally, because of the emerging role of mastocytes in 
driving diffuse alveolar injury in COVID-19 [47], it should be recalled that magnesium reduces mastocyte degranulation and, subsequently, prevents the release of inflammatory, pro-thrombotic and fibrotic mediators [48]. Accordingly, famotidine, an antagonist of histamine $\mathrm{H} 2$ receptors, seems to mitigate COVID-19 symptoms caused by dysfunctional mast cell activation and histamine release [49].

A recent paper demonstrates that low magnesium reduces diaphragm function in an experimental model of sepsis [50]. If confirmed in humans, these results suggest that magnesium deficiency might lead to the need of assisted ventilation by impairing diaphragm contraction and, therefore, breathing.

On these bases, there is a plausible pathophysiological basis to support that magnesium is among the missing keys linking chronic diseases with the severity and prognosis of COVID-19.

\section{Magnesium in infectious diseases}

Most findings regarding the direct association between magnesium status and immune function are derived from animal models. In humans, the fundamental importance of magnesium in immunity and the underlying mechanisms have been highlighted by the discovery of the primary immunodeficiency XMEN (X-linked immunodeficiency with magnesium defect, Epstein-Barr virus infection, and neoplasia), which is characterized by chronic Epstein-Barr virus infection [51]. However, general evidence that magnesium deficiency may confer a higher predisposition to infectious diseases is mostly indirect [34]. An optimal magnesium status is necessary for the synthesis, transport, and activation of vitamin D [52]. Vitamin D is an immunomodulatory hormone, and vitamin $\mathrm{D}$ deficit has been linked to various infectious diseases, including upper respiratory and enteric infections, pneumonia, otitis media, Clostridium infections, vaginosis, urinary tract infections, sepsis, influenza, dengue, hepatitis B, hepatitis C, and HIV infections [53]. Accordingly, a number of clinical trials aiming to determine the efficacy of administration of vitamin D and its metabolites for treatment of these diseases have been conducted, but have rarely shown benefits as therapeutic or preventive measures. Nevertheless, an important exception to the general trend is for upper respiratory tract infections. A meta-analysis involving 25 randomized controlled trials (RCTs) and data from 10,933 participants showed that vitamin D supplementation reduced the risk of acute respiratory tract infection among all participants [54]. The close relationship between magnesium and vitamin D suggests that the higher incidence of infectious diseases associated with vitamin D deficiency can be at least in part explained by a deficit of magnesium, and this may be particularly relevant in the respiratory tract.
Altered magnesium status also seems to have a prognostic role in older people affected by bacterial pneumonia. Hypomagnesemia and hypermagnesemia were both associated with excessive short-term mortality, $18.4 \%$ and $50 \%$, respectively, compared to normal values of serum magnesium [55]. Moreover, low serum magnesium status was a significant predictor of frequent readmissions for acute exacerbation of chronic obstructive pulmonary disease in a retrospective study on older adults [56].

More relevantly, in a cohort of 144 adults who were hospitalized with SARS-CoV-1 infection in the greater Toronto area in the 2003 epidemic, hypomagnesemia was found in many patients on admission, and tended to worsen during hospitalization [57]. It was unclear whether this represented the natural history of the disease or was secondary to effects of ribavirin or other therapies on renal tubular function. Indeed, after adjusting for SARS-CoV-1 -related prognostic factors and corticosteroid use, ribavirin use in 306 SARS patients was strongly associated with hypomagnesemia, and the risk of hypomagnesemia attributable to ribavirin use was $45 \%$ [58]. Since ribavirin is also currently employed for compassionate use in COVID-19 patients with respiratory distress, these findings stress the importance of evaluating and, if necessary, correcting magnesemia. Although in a different context, an animal study suggested that hypomagnesemia might be a common adverse effect of other antiviral therapies, and might potentiate the risk of cardiovascular complications, while magnesium supplementation is protective [59].

On the other hand, in quest of more effective first-line treatments for COVID-19, several in silico docking studies have been published for the repurposing of existing antivirals. Interestingly, binding of several candidate drugs to their viral target is dependent on magnesium, which is not surprising in view of its biochemical properties [60, 61]. It is tempting to speculate that the pharmacological activity of the drugs under investigation for treatment of COVID19 patients might be dependent on the intracellular magnesium concentration and that magnesium deficits may reduce efficacy.

In conclusion, very little is known on the prevalence and significance of hypomagnesemia in infectious diseases. Nevertheless, the current pandemic has raised unprecedented research efforts that are unveiling intriguing relationships between magnesium status and the clinical course of COVID-19.

\section{Links between magnesium derangements and COVID-19 pathogenesis}

As knowledge about the pathogenesis of COVID-19 has increased, more hints illuminate the potential role of 


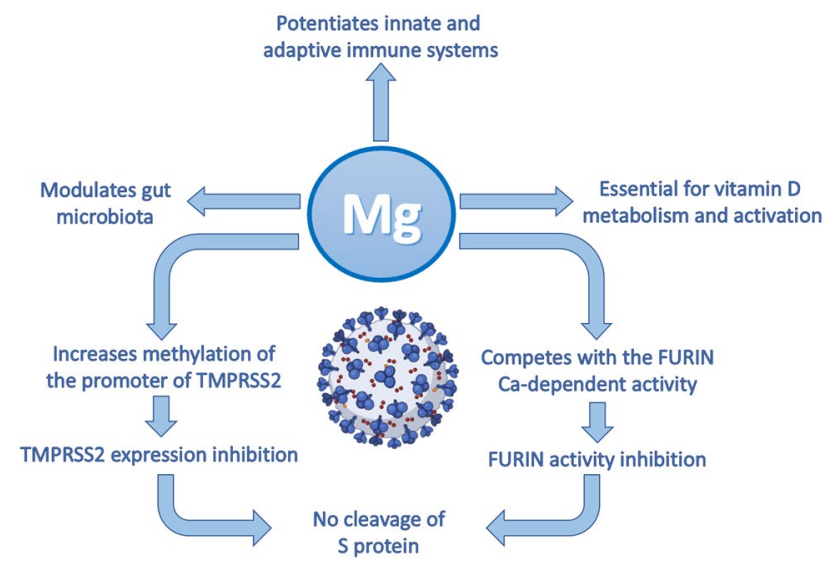

Fig. 1 How magnesium might contribute to protecting against COVID-19. Magnesium modulates innate and adaptive immunity and gut microbiota composition, and is essential for Vitamin D activation and its consequent anti-inflammatory activity. Crucial steps of SARS$\mathrm{CoV}-2$ infection might be directly affected by magnesium

dysregulated magnesium homeostasis in the prevention and clinical trend of the disease (Fig. 1).

First issue to recall is that magnesium tunes the activity of the innate and adaptive immune systems.

It stabilizes the membranes of mastocytes, localized in the submucosa of the airways and the alveolar septa, thereby preventing their degranulation and the release of a myriad of mediators [62]. Magnesium regulates the activity of neutrophils and macrophages, inhibits their priming and oxidative burst, and also hinders the Toll-like receptor 4/NFкB axis [62]. In lymphocytes, magnesium controls the amounts of IP3 and DAG, important second messengers activated after the engagement of B and T cell receptors [63]. Importantly, magnesium protects against viral infections because adequate intracellular magnesium concentrations are required for the cytotoxic activity of T lymphocytes and natural killer (NK) cells [64]. Beyond potentiating and harmonizing immune function, it is emerging that magnesium levels might influence initial events of SARS-CoV-2 infection. The viral spike (S) protein binds the entry receptor, the angiotensin-converting enzyme 2 (ACE2), expressed in many tissues, thus accounting for pulmonary and extrapulmonary manifestations of COVID19 [13]. For fusion between viral and cell membranes to occur, the $\mathrm{S}$ protein needs to be proteolytically cleaved by host cell proteases, mainly the transmembrane protease serine protease 2 (TMPRSS2) and the pre-protein convertase furin [65]. Magnesium might play a role in inhibiting the activity of these enzymes. Preliminary results suggest that magnesium treatment increases the methylation of the promoter of TMPRSS2, thus hindering transcription and, consequently, reducing the expression of the enzyme [66]. Moreover, thanks to its calcium antagonistic function, magnesium might hamper the activity of the calciumdependent furin [67]. It follows that magnesium deficiency may promote virus infectivity. Once the infection is ongoing, magnesium deficiency can exacerbate the inflammatory response contributing to the so-called cytokine storm that is involved in the pathogenesis of severe SARS-CoV-2 clinical manifestations. The immune system reaction to the coronavirus may be so overwhelming and inappropriate as to jeopardize the lungs and the other tissues more than the virus itself, endangering the survival of patients. Notably, low levels of magnesium associate also with increased amounts of inflammatory mediators [16, 62], among which platelet activating factor (PAF) [68]. PAF is a key player in COVID-19, being implicated in generating microthrombosis and promoting respiratory distress $[69,70]$.

Although some controversies exist, a recent metanalysis reports that low serum levels of 25-hydroxyvitamin D (25-OHD) are associated with a higher susceptibility to SARS-CoV-2 infection, COVID-19 severity and mortality [71]. Indeed, as highlighted in the previous section, vitamin $\mathrm{D}$ is necessary for a healthy immune system. The activity of vitamin $\mathrm{D}$ is strictly intertwined with magnesium [34]. Clearly, magnesium deficiency leads to reduced amounts of active vitamin $\mathrm{D}$, thus generating a fertile soil for SARS-CoV-2 infection.

A last issue to mention is the recent finding that magnesium deficiency alters the delicate balance between gut microbiota and the host [72, 73], thus influencing the airway microbiota and the immune response [74]. Lately, the relation between microbiota dysbiosis and COVID19 severity has attracted the attention of the scientific community [75, 76] and hopefully new hints will soon be available.

\section{Magnesium in COVID-19: clinical studies}

As delineated in the previous sections, the key role of magnesium in maintaining proper immune, vascular and pulmonary function strongly supports the hypothesis that magnesium status may affect the susceptibility and the response to SARS-CoV-2. Indeed, a few recent reports have analyzed magnesium levels in COVID-19 patients and assessed their association with disease outcomes (Table 1).

Zeng et al. [77] analyzed over 300 patients and found that severe cases (defined as those having oxygen saturation $\leq 93 \%$ at rest, or $\mathrm{PaO}_{2} / \mathrm{FiO}_{2} \leq 300 \mathrm{mmHg}$, or requiring 
Table 1 Existing clinical studies showing alterations of magnesium levels in COVID-19 patients

\begin{tabular}{|c|c|c|c|}
\hline Study Design & $\begin{array}{l}\text { Num- } \\
\text { ber of } \\
\text { patients }\end{array}$ & Outcome & References \\
\hline Retrospective & 300 & Severe cases have lower magnesium levels than mild and moderate cases & [73] \\
\hline Retrospective & 459 & Low magnesium levels are associated to mortality & [74] \\
\hline Prospective & 300 & $\begin{array}{l}48 \% \text { of hospitalized patients are hypomagnesemic, but hypermagnesemia is more prevalent in ICU } \\
\text { cases }\end{array}$ & {$[75]$} \\
\hline Prospective & 200 & $\begin{array}{l}\text { In pregnant women, SARS-CoV2 infection was associated to higher magnesemia in the first and third } \\
\text { semester in comparison to non-infected subjects }\end{array}$ & [76] \\
\hline Cross-sectional & 58 & $\begin{array}{l}\text { An altered magnesium status (either hypomagnesemia or hypermagnesemia) was more frequent in } \\
\text { ICU cases }\end{array}$ & [77] \\
\hline Retrospective & 90 & Patients show levels of calcium and magnesium lower than controls & [78] \\
\hline Retrospective & 320 & $\begin{array}{l}\text { Serum calcium and magnesium concentration were significantly lower in hypokalemic than normoka- } \\
\text { lemic patients }\end{array}$ & [79] \\
\hline Case report & 1 & $\begin{array}{l}\text { Persistent hypokalemia and hypomagnesemia, which continued for more than } 5 \text { months after the initial } \\
\text { infection and its resolution }\end{array}$ & {$[80]$} \\
\hline
\end{tabular}

ICU care) showed significant lower levels of magnesium than mild and moderate cases, though all values remained within the reference range. Such difference was found consistently over the clinical course since disease onset. In addition, low magnesium levels were indicated as risk factor for mortality in COVID-19 patients. A retrospective research on a total of 459 confirmed cases found that in the 63 expired individuals magnesium levels on admission were significantly lower than in the 396 survivors $(1.61 \pm 0.19$ vs. $1.81 \pm 0.23 \mathrm{mg} / \mathrm{dl}$, respectively) [78] Quilliot et al. [79] performed a detailed analysis of magnesemia and associated factors in a cohort of 300 patients. Among these, $48 \%$ had a magnesemia below $0.75 \mathrm{mmol} / \mathrm{L}$, including $13 \%$ of severely hypomagnesemic patients $(0.65 \mathrm{mmol} / \mathrm{L})^{1}$; on the other hand, a small proportion of patients $(9.6 \%)$ was hypermagnesemic $(>0.95 \mathrm{mmol} / \mathrm{L})$. In this study, in moderate cases of COVID-19, serum magnesium concentrations were significantly lower and the prevalence of hypomagnesemia was significantly higher than in critical cases, whereas the prevalence of hypermagnesemia was significantly increased in ICU cases. It is intriguing that in pregnant women, SARS-CoV2 infection was associated to significantly higher magnesemia in the first and third semester in comparison to non-infected subjects; however, magnesium levels did not correlate with disease severity in this cohort [80].

A frequent confounding factor in the cited studies may be that individuals with comorbidities, such as hypertension, cardiovascular diseases, diabetes, and obesity, who are more prone to develop severe COVID-19, often show altered

\footnotetext{
${ }_{1}$ Magnesemia is expressed in $\mathrm{mmol} / \mathrm{L}$ or $\mathrm{mg} / \mathrm{dL}$ (conversion: $\mathrm{mmol} / \mathrm{L}=\mathrm{mg} / \mathrm{dL} \times 0.4114)$.
}

magnesium levels. In this respect, it is worth mentioning a small cohort study by Sarvazad et al. [81]. They analyzed the electrolyte status in COVID-19 patients on hospital admission, but patients with a history of cancer, diabetes, hypertension, or cardiovascular and renal disorders were excluded from the study. Overall, out of 50 patients with no previous underlying disease, $32 \%$ were found to be hypomagnesemic $(1.26 \%-1.7 \mathrm{mg} / \mathrm{dl}), 6 \%$ were severely hypomagnesemic $(<1.25 \mathrm{mg} / \mathrm{dl})$ and $14 \%$ were hypermagnesemic $(>2.6 \mathrm{mg} /$ dl). Most importantly, an altered magnesium status (either hypomagnesemia or hypermagnesemia) was more frequently found in the ICU cases compared to the outpatients.

Derangement in magnesium homeostasis may have multifold consequences. Secondary to hypomagnesemia, disturbances of potassium and calcium handling are often detected; when serum magnesium levels are low, hypokalemia and hypocalcemia may be refractory to treatment by supplementation unless magnesemia is concomitantly corrected [25]. Both $\mathrm{K}^{+}$and $\mathrm{Ca}^{2+}$ imbalances have been described in COVID-19 patients, and in some instances were associated to altered magnesium levels. Al-Hakeim et al. [82] reported preliminary findings showing lower levels of both calcium and magnesium in 60 COVID-19 patients in comparison to 30 matched controls. Importantly, calcium and magnesium levels positively correlated with oxygen saturation levels. A retrospective, observational study was conducted on 320 non-critically ill patients [83]. In this cohort, serum calcium and magnesium concentration were significantly lower in hypokalemic than normokalemic patients, and $18.4 \%$ of hypokalemic patients was also frankly hypomagnesemic. Furthermore, patients who experienced hypokalemia had significantly longer hospitalization than controls. A case report [84] suggested that electrolyte imbalances may persist in the long term. A COVID-19 patient was 
admitted with low potassium levels, but normal magnesiuim levels, but during his hospitalization developed persistent hypokalemia and hypomagnesemia, which continued for more than 5 months after the initial infection and its resolution.

It is hard to extrapolate a univocal conclusion from the existing evidence, that was obtained from a variety of populations, employing different measuring techniques and different reference values. The long-standing debate about the magnesium reference range, as well as the lack of consensus about the most appropriate indicators of magnesium status, are just one side of the story [6]. The main problem lies in the paucity of studies that have been appositely designed to investigate the role of magnesium in COVID-19 clinical course. All the studies that we have reviewed so far have inherent flaws, mostly due to their observational nature. In most studies, anomalies in magnesium were simply incidental findings that did not undergo further analysis. Magnesium levels in adequately matched controls were rarely provided. Notably, in most cases, magnesium values were simply "snapshot" values, taken on admission or at an undetermined time during hospitalization. We do not know magnesium levels before infection, nor their evolution during the course of the disease. Information on nutritional habits, medications or dietary supplements is missing.

Despite all limitations, existing data seem to corroborate an association between deranged magnesium homeostasis and COVID-19. The occurrence of hypermagnesemia in ICU cases in the absence of nephropathy, evidenced by two studies [79, 81], is an intriguing finding that might be related to rapid mobilization from soft tissues in patients with sepsis or to necrotic events due to microvascular thrombosis. Therefore, this finding may not necessarily be in contrast with data that indicate hypomagnesemia as a risk factor for developing complications.

Unfortunately, at present we do not possess enough knowledge to answer to some fundamental questions. Is magnesium deficiency a risk factor for developing COVID19 ? In other words, are magnesium-deficient individuals more prone to infection? Or vice versa, does infection lower magnesium levels? And in either case, do magnesium levels affect the clinical course of the disease? An affirmative and conclusive answer to these questions would offer new prophylactic or therapeutical opportunities by an intervention as simple as magnesium supplementation. Therefore, we urgently need to design further and better studies to clarify these issues. At present, we are aware of just one interventional study involving magnesium supplementation in COVID-19 patients that has been published [85]. In a cohort of 43 patients ( $>50$ years of age), seventeen patients received a combination of vitamin $\mathrm{D}$, magnesium and vitamin B12 (DMB) before requiring any form of oxygen therapy, intensive care support, or both. The intervention group showed a significant reduction in the proportion of patients clinically deteriorating. The protective effect of DMB supplementation was retained after adjusting for age and hypertension. Further promising work is ongoing [86-88] (Table 2).

\section{Magnesium and Post-Acute COVID-19 Syndrome}

Similarly to post-acute viral syndromes observed in survivors of other virulent coronavirus epidemics (e.g., SARS and MERS), increasing reports describe persistent and prolonged effects after acute COVID-19 [3]. Long COVID affects the lungs, the brain, the heart, the gastrointestinal system, and the kidney. Patients most commonly experience hair loss, fatigue, muscular weakness and joint pain, arthralgia, followed by dyspnea/cough, and chest pain/palpitation. Neurological symptoms are also frequent: headache, sleep disorders, anxiety/depression and cognitive disturbances, in particular clouding of consciousness called "brain fog" (Fig. 2). According to epidemiological studies, a high percentage of hospitalized and non-hospitalized COVID-19 survivors have at least one symptom up to 2-6 months after infection. Overall, these symptoms lead to a decline in the quality of life and increase frailty, and represent a current concern calling for multidisciplinary management of the post-acute phase of the disease.

The mechanisms involved in the pathophysiology of long COVID syndrome are multifactorial and include direct virus-induced alterations, immunologic aberration and inflammatory damage in response to the acute infection, as well as ischemia due to microvascular thromboembolism, immobility and metabolic derangements, the latter being associated with the PTSD (Post Traumatic Stress Disorder). The simultaneous occurrence of chronic fatigue, dyspnea, pain and cough suggest the possibility of alterations in the brain. Interestingly, SARS-CoV-2 has neuro-invasion capacity and sensory neurons seem to be its entry point to the central nervous system (CNS) [89]. Furthermore, neuroinflammatory events driven by the cytokine storm are likely to affect various regions of the CNS [90].

In this context, it is noteworthy that in the brain magnesium affects multiple biochemical processes involved in cognitive functions, cell membrane stability and integrity, NMDAreceptor response to excitatory stimuli. It also exerts a calcium-antagonist action and combats neuroinflammation [40]. Consistently, magnesium deficit determines anxiety, insomnia, hyperemotionality, depression, headache, light-headedness [40], symptoms included in the post-acute COVID-19 syndrome. Moreover, magnesium deficits have been suggested to cause weakness and muscle pain. This is not surprising since magnesium is key for all the enzymes utilizing or synthesizing muscle ATP, and thus for the production of muscle energy, and also regulates contraction and relaxation [25]. Additionally, 
Table 2 Ongoing clinical studies investigating the role of magnesium in COVID-19

\begin{tabular}{|c|c|c|c|}
\hline Study Design & Clinical Center & $\begin{array}{l}\text { Num- } \\
\text { ber of } \\
\text { Patients }\end{array}$ & Outcome \\
\hline Interventional RCT [84] & $\begin{array}{l}\text { Masih Daneshvari Hospital, Shahid Dr. } \\
\text { Labbafinejad Hospital, Shahid Sadoughi } \\
\text { Hospital, Iran }\end{array}$ & 100 & $\begin{array}{l}\text { Improvement of respiratory function and symp- } \\
\text { toms upon inhalation of } \mathrm{MgSO}_{4}\end{array}$ \\
\hline Interventional RCT & $\begin{array}{l}\text { Mexican Social Security Institute at Durango, } \\
\text { Mexico }\end{array}$ & 100 & $\begin{array}{l}\text { Reduction of the probability of infection and } \\
\text { the need for hospitalization and/or mortality } \\
\text { upon administration of } \mathrm{MgCl}_{2} \text { plus vitamin } \mathrm{D}\end{array}$ \\
\hline Interventional & University of Minnesota, USA & NA & $\begin{array}{l}\text { Efficacy of } \mathrm{Mg} \text { supplementation for preventing } \\
\text { sudden cardiac death in hypertensive patients }\end{array}$ \\
\hline Prospective & $\begin{array}{l}\text { AOU San Giovanni di Dio e Ruggi } \\
\text { D'Aragona, University of Salerno, Italy }\end{array}$ & 100 & $\begin{array}{l}\text { Correlation between total and ionized serum } \\
\text { Mg levels and outcomes in ICU patients }\end{array}$ \\
\hline Prospective & $\begin{array}{l}\text { National Research Institute of Tuberculosis } \\
\text { and Lung Diseases, Iran }\end{array}$ & 200 & $\begin{array}{l}\text { Correlation between serum } \mathrm{Mg} / \mathrm{Ca} \text { level and } \\
\text { CRP in ICU patients }\end{array}$ \\
\hline Retrospective and Prospective [85] & $\begin{array}{l}\text { Academy of Nutrition and Dietetics / George } \\
\text { Mason University, USA }\end{array}$ & 250 & $\begin{array}{l}\text { Correlation between nutrition standard care } \\
\text { practices and outcomes in ICU patients }\end{array}$ \\
\hline Retrospective & University of Milan - Ospedale Sacco, Italy & 430 & $\begin{array}{l}\text { Correlation between Mg levels and the course } \\
\text { of COVID-19 }\end{array}$ \\
\hline Retrospective & AUSL-IRCCS Reggio Emilia, Italy & 241 & $\begin{array}{l}\text { Correlation between Mg levels and COVID-19 } \\
\text { outcomes }\end{array}$ \\
\hline Retrospective [86] & University Hospital of Puebla, Mexico & 118 & $\begin{array}{l}\text { Correlation between renal function, serum } \\
\text { magnesium levels and mortality in T2D } \\
\text { patients }\end{array}$ \\
\hline Retrospective & $\begin{array}{l}\text { Comenius University in Bratislava -Biomedi- } \\
\text { cal Centre Martin at Jessenius Faculty of } \\
\text { Medicine, and the Hospitals of Žilina self- } \\
\text { governing region, Slovakia }\end{array}$ & 300 & $\begin{array}{l}\text { Correlation between Mg levels (and of other } \\
\text { bio-elements) and the course of COVID-19 }\end{array}$ \\
\hline Retrospective & Indiana University, USA & NA & $\begin{array}{l}\text { Associations between nutritional status of } \\
\text { vitamin D, iron, and magnesium and disease } \\
\text { severity of COVID-19 }\end{array}$ \\
\hline Cross-sectional & $\begin{array}{l}\text { Mexican Social Security Institute at Durango, } \\
\text { Specialty Hospital from the National Medi- } \\
\text { cal Center Century XXI, Mexican Social } \\
\text { Security Institute at Mexico City, Mexico }\end{array}$ & 450 & $\begin{array}{l}\text { Correlation between hypomagnesemia and } \\
\text { COVID-19 mortality }\end{array}$ \\
\hline
\end{tabular}

NA Not available

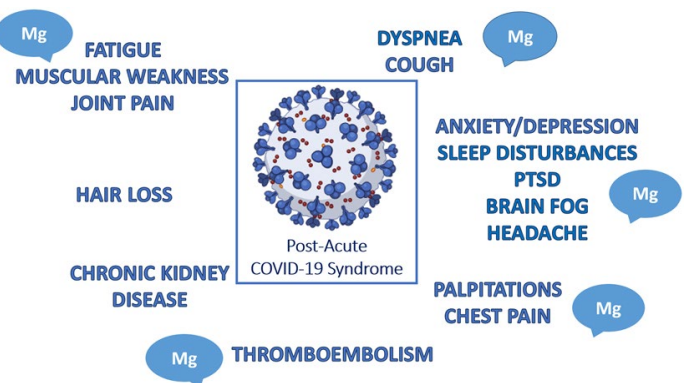

Fig. 2 How magnesium deficiency might contribute to the long COVID-19 syndrome. Among the symptoms of post-acute COVID19 syndrome summarized in the figure, many are often associated to hypomagnesaemia, i.e., muscular-related symptoms, pulmonary distress, neurologic and behavioral disorders, some arrhytmias, hypercoagulation disorders. These symptoms may benefit from a magnesiumrich diet or, if necessary, magnesium supplementation. PTSD Post Traumatic Stress Disorders, including physical, cognitive, and psychiatric symptoms magnesium assures the regenerative capacity of skeletal muscle fibers [91].

In conclusion, an altered magnesium homeostasis might reasonably contribute to and aggravate long COVID syndrome (Fig. 2). Therefore, assessing and, if necessary, correcting magnesaemia is essential to support full recovery. It is clear that care for patients with COVID-19 does not end at the time of hospital discharge, and comprehensive care of recovered patients is needed in the outpatient setting as well.

In this respect, magnesium supplementation is a safe and cost-effective intervention that could help restoring the severely deranged homeostatic equilibrium of the body. 


\section{Conclusions}

The ongoing SARS-CoV-2 pandemic dramatically impacted on health and economy, and has significantly constrained social and cultural rights. Intervention strategies to cope with SARS-CoV-2 infection are in their early stages and we need proof of clinical efficacy. We propose to consider the relevance of magnesium, frequently overlooked in clinical practice. It is therefore relevant to include magnesium in the ionogram to diagnose alterations of magnesium homeostasis, which might represent one of the many dowels that contribute to complete the complex mosaic of signs and symptoms of acute and long COVID-19.

Monitoring and restoring magnesium homeostasis through an appropriate nutritional regimen or eventually by supplementation should therefore be taken in account for the general population, in particular during the current pandemic, as magnesium might contribute to prevent SARSCoV-2 infection, to reduce severity of COVID-19 symptoms and to facilitate the recovery after the acute phase.

Acknowledgements The Authors wish to thank Martin Kolisek, Massimo Galli, Stefano Rusconi, Stefania Caronni, Letizia Oreni, Lucia Merolle, Roberto Baricchi, Paolo Giorgi Rossi, Pamela Mancuso, Tommaso Fasano, Ornella Piazza, Taylor Wallace, Nana Gletsu-Miller, Martha Rodriguez-Moran, and Moises Mercado-Atri for their contribution in the clinical studies listed in Table 2.

Author contributions JAM and FIW conceptualization; JAM and VT writing-original draft; all authors, writing-review and editing.

Funding This work did not receive external funding.

\section{Declarations}

Conflict of interest The authors declare no conflict of interest.

Open Access This article is licensed under a Creative Commons Attribution 4.0 International License, which permits use, sharing, adaptation, distribution and reproduction in any medium or format, as long as you give appropriate credit to the original author(s) and the source, provide a link to the Creative Commons licence, and indicate if changes were made. The images or other third party material in this article are included in the article's Creative Commons licence, unless indicated otherwise in a credit line to the material. If material is not included in the article's Creative Commons licence and your intended use is not permitted by statutory regulation or exceeds the permitted use, you will need to obtain permission directly from the copyright holder. To view a copy of this licence, visit http://creativecommons.org/licenses/by/4.0/.

\section{References}

1. (2021) WHO COVID-19 Dashboard. https://covid19.who.int/. (Accessed 18 Jun 2021)

2. Singh R, Kang A, Luo X et al (2021) COVID-19: Current knowledge in clinical features, immunological responses, and vaccine development. FASEB J Off Publ Fed Am Soc Exp Biol 35:e21409. https://doi.org/10.1096/fj.202002662R

3. Nalbandian A, Sehgal K, Gupta A et al (2021) Post-acute COVID19 syndrome. Nat Med 27:601-615. https://doi.org/10.1038/ s41591-021-01283-Z

4. Fan Y, Pedersen O (2021) Gut microbiota in human metabolic health and disease. Nat Rev Microbiol 19:55-71. https://doi.org/ 10.1038/s41579-020-0433-9

5. Medeiros de Morais C (2021) Nutritional therapy in COVID-19 management. Kompass Nutr Diet 1:10-12. https://doi.org/10. $1159 / 000512853$

6. Wolf FI, Maier JA, Rosanoff A et al (2021) The magnesium global network (MaGNet) to promote research on magnesium in diseases focusing on COVID-19. Magnes Res 34:90-92. https://doi.org/10. 1684/mrh.2021.0479

7. Iotti S, Wolf F, Mazur A, Maier JA (2020) The COVID-19 pandemic: is there a role for magnesium? Hypotheses and perspectives. Magnes Res 33:21-27. https://doi.org/10.1684/mrh.2020. 0465

8. Micke O, Vormann J, Kisters K (2020) Magnesium deficiency and COVID- 19 - What are the links? Trace Elem Electrolytes 37:103-107. https://doi.org/10.5414/tex01651

9. Wallace TC (2020) Combating COVID-19 and building immune resilience: a potential role for magnesium nutrition? J Am Coll Nutr 39:685-693. https://doi.org/10.1080/07315724.2020.17859 71

10. Harrison SL, Fazio-Eynullayeva E, Lane DA et al (2020) Comorbidities associated with mortality in 31,461 adults with COVID19 in the United States: a federated electronic medical record analysis. PLoS Med 17:e1003321. https://doi.org/10.1371/journ al.pmed. 1003321

11. Salinas Aguirre JE, Sánchez García C, Rodríguez Sanchez R, et al (2021) [Clinical characteristics and comorbidities associated with mortality in patients with COVID-19 in Coahuila (Mexico)]. Rev Clin Esp

12. Cazzola R, Della Porta M, Manoni M et al (2020) Going to the roots of reduced magnesium dietary intake: a tradeoff between climate changes and sources. Heliyon 6:e05390. https://doi.org/ 10.1016/j.heliyon.2020.e05390

13. Gupta A, Madhavan MV, Sehgal K et al (2020) Extrapulmonary manifestations of COVID-19. Nat Med 26:1017-1032. https://doi. org/10.1038/s41591-020-0968-3

14. Goshua G, Pine AB, Meizlish ML et al (2020) Endotheliopathy in COVID-19-associated coagulopathy: evidence from a single-centre, cross-sectional study. Lancet Haematol 7:e575-e582. https:// doi.org/10.1016/S2352-3026(20)30216-7

15. Perico L, Benigni A, Casiraghi F et al (2021) Immunity, endothelial injury and complement-induced coagulopathy in COVID-19. Nat Rev Nephrol 17:46-64. https://doi.org/10.1038/ s41581-020-00357-4

16. Maier JAM (2012) Endothelial cells and magnesium: implications in atherosclerosis. Clin Sci (Lond) 122:397-407. https://doi.org/ 10.1042/CS20110506

17. Sheu J-R, Hsiao G, Shen M-Y et al (2002) Mechanisms involved in the antiplatelet activity of magnesium in human platelets. $\mathrm{Br} \mathrm{J}$ Haematol 119:1033-1041. https://doi.org/10.1046/j.1365-2141. 2002.03967.x

18. Rubin H (2005) Magnesium: the missing element in molecular views of cell proliferation control. BioEssays 27:311-320. https:// doi.org/10.1002/bies.20183

19. Kubota T, Shindo Y, Tokuno K et al (2005) Mitochondria are intracellular magnesium stores: investigation by simultaneous fluorescent imagings in PC12 cells. Biochim Biophys Acta 1744:19-28. https://doi.org/10.1016/j.bbamcr.2004.10.013

20. Iotti S, Frassineti C, Sabatini A et al (2005) Quantitative mathematical expressions for accurate in vivo assessment of cytosolic 
[ADP] and DeltaG of ATP hydrolysis in the human brain and skeletal muscle. Biochim Biophys Acta 1708:164-177. https:// doi.org/10.1016/j.bbabio.2005.01.008

21. Feeney KA, Hansen LL, Putker M et al (2016) Daily magnesium fluxes regulate cellular timekeeping and energy balance. Nature 532:375-379. https://doi.org/10.1038/nature17407

22. Li F, Chaigne-delalande B, Kanellopoulou C et al (2012) Signaling role for $\mathrm{Mg} 2+$ revealed by immunodeficiency due to loss of MagT1. Nature 475:471-476. https://doi.org/10.1038/natur e10246.Signaling

23. Caspi R, Billington R, Keseler IM et al (2020) The MetaCyc database of metabolic pathways and enzymes - a 2019 update. Nucleic Acids Res 48:D445-D453. https://doi.org/10.1093/nar/gkz862

24. Fiorentini D, Cappadone C, Farruggia G, Prata C (2021) Magnesium: biochemistry, nutrition, detection, and social impact of diseases linked to its deficiency. Nutrients 13:1136. https://doi. org/10.3390/nu13041136

25. de Baaij JHF, Hoenderop JGJ, Bindels RJM (2015) Magnesium in man: implications for health and disease. Physiol Rev 95:146. https://doi.org/10.1152/physrev.00012.2014

26. Huang Y, Jin F, Funato Y et al (2021) Structural basis for the $\mathrm{Mg}(2+)$ recognition and regulation of the CorC $\mathrm{Mg}(2+)$ transporter. Sci Adv 7:eabe6140. https://doi.org/10.1126/sciadv. abe6140

27. Workinger JL, Doyle RP, Bortz J (2018) Challenges in the diagnosis of magnesium status. Nutrients 10:1202. https://doi.org/ 10.3390/nu10091202

28. Arnaud MJ (2008) Update on the assessment of magnesium status. Br J Nutr 99(Suppl 3):S24-36. https://doi.org/10.1017/ S000711450800682X

29. Costello RB, Nielsen F (2017) Interpreting magnesium status to enhance clinical care: key indicators. Curr Opin Clin Nutr Metab Care 20:504-511. https://doi.org/10.1097/MCO.00000 00000000410

30. Arinzon Z, Peisakh A, Schrire S, Berner YN (2010) Prevalence of hypomagnesemia (HM) in a geriatric long-term care (LTC) setting. Arch Gerontol Geriatr 51:36-40. https://doi.org/10. 1016/j.archger.2009.07.002

31. Hyassat D, Al Sitri E, Batieha A et al (2014) Prevalence of hypomagnesaemia among obese type 2 diabetic patients attending the national center for diabetes, endocrinology and genetics (NCDEG). Int J Endocrinol Metab 12:e17796. https://doi.org/ 10.5812/ijem. 17796

32. Rabeea IS, Al-Gburi K, Adnan I et al (2020) Pattern and correlates of hypomagnesemia among subset of diabetes mellitus. Curr Diabetes Rev 16:364-369. https://doi.org/10.2174/15733 99814666181026095236

33. Rodríguez-Ramírez M, Simental-Mendía LE, González-Ortiz $M$ et al (2015) Prevalence of prehypertension in mexico and its association with hypomagnesemia. Am J Hypertens 28:10241030. https://doi.org/10.1093/ajh/hpu293

34. Dominguez LJ, Veronese N, Guerrero-Romero F, Barbagallo M (2021) Magnesium in infectious diseases in older people. Nutrients 13:180. https://doi.org/10.3390/nu13010180

35. Wu J, Xun P, Tang Q et al (2017) Circulating magnesium levels and incidence of coronary heart diseases, hypertension, and type 2 diabetes mellitus: a meta-analysis of prospective cohort studies. Nutr J 16:60. https://doi.org/10.1186/s12937-017-0280-3

36. Chrysant SG, Chrysant GS (2019) Association of hypomagnesemia with cardiovascular diseases and hypertension. Int J Cardiol Hypertens 1:100005. https://doi.org/10.1016/j.ijchy.2019. 100005

37. Reffelmann T, Ittermann T, Dörr M et al (2011) Low serum magnesium concentrations predict cardiovascular and all-cause mortality. Atherosclerosis 219:280-284. https://doi.org/10.1016/j. atherosclerosis.2011.05.038
38. Upala S, Jaruvongvanich V, Wijarnpreecha K, Sanguankeo A (2016) Hypomagnesemia and mortality in patients admitted to intensive care unit: a systematic review and meta-analysis. QJM 109:453-459. https://doi.org/10.1093/qjmed/hcw048

39. Piuri G, Zocchi M, Della Porta M et al (2021) Magnesium in obesity, metabolic syndrome, and type 2 diabetes. Nutrients 13:320. https://doi.org/10.3390/nu13020320

40. Barbagallo M, Veronese N, Dominguez LJ (2021) Magnesium in aging, health and diseases. Nutrients 13:463. https://doi.org/10. 3390/nu13020463

41. Barbagallo M, Dominguez LJ (2015) Magnesium and type 2 diabetes. World J Diabetes 6:1152-1157. https://doi.org/10.4239/wjd. v6.i10.1152

42. Veronese N, Demurtas J, Pesolillo G et al (2020) Magnesium and health outcomes: an umbrella review of systematic reviews and meta-analyses of observational and intervention studies. Eur J Nutr 59:263-272. https://doi.org/10.1007/s00394-019-01905-w

43. Britton J, Pavord I, Richards K et al (1994) Dietary magnesium, lung function, wheezing, and airway hyperreactivity in a random adult population sample. Lancet (London, England) 344:357-362. https://doi.org/10.1016/s0140-6736(94)91399-4

44. Dominguez LJ, Barbagallo M, Di Lorenzo G et al (1998) Bronchial reactivity and intracellular magnesium: a possible mechanism for the bronchodilating effects of magnesium in asthma. Clin Sci (Lond) 95:137-142

45. Sarhan HA, El-Garhy OH, Ali MA, Youssef NA (2016) The efficacy of nebulized magnesium sulfate alone and in combination with salbutamol in acute asthma. Drug Des Devel Ther 10:19271933. https://doi.org/10.2147/DDDT.S103147

46. Pooransari P, Pourdowlat G (2020) Magnesium sulfate. a potential adjuvant treatment on COVID-19. Front Emerg Med 4:19-20. https://doi.org/10.22114/ajem.v0i0.508

47. Theoharides TC (2021) Potential association of mast cells with coronavirus disease 2019. Ann Allergy, asthma Immunol Off Publ Am Coll Allergy Asthma Immunol 126:217-218. https://doi.org/ 10.1016/j.anai.2020.11.003

48. Zierler S, Sumoza-Toledo A, Suzuki S et al (2016) TRPM7 kinase activity regulates murine mast cell degranulation. J Physiol 594:2957-2970. https://doi.org/10.1113/JP271564

49. Malone RW, Tisdall P, Fremont-Smith P et al (2021) COVID-19: famotidine, histamine, mast cells, and mechanisms. Front Pharmacol 12:633680. https://doi.org/10.3389/fphar.2021.633680

50. Jiang J, Chen Q, Chen X et al (2020) Magnesium sulfate ameliorates sepsis-induced diaphragm dysfunction in rats via inhibiting HMGB1/TLR4/NF-кB pathway. NeuroReport 31:902-908. https://doi.org/10.1097/WNR.0000000000001478

51. Ravell JC, Chauvin SD, He T, Lenardo M (2020) An update on XMEN disease. J Clin Immunol 40:671-681. https://doi.org/10. 1007/s10875-020-00790-x

52. Dai Q, Zhu X, Manson JE et al (2018) Magnesium status and supplementation influence vitamin D status and metabolism: results from a randomized trial. Am J Clin Nutr 108:1249-1258. https:// doi.org/10.1093/ajen/nqy274

53. Charoenngam N, Holick MF (2020) Immunologic effects of vitamin D on human health and disease. Nutrients 12:2097. https:// doi.org/10.3390/nu12072097

54. Martineau AR, Jolliffe DA, Hooper RL et al (2017) Vitamin D supplementation to prevent acute respiratory tract infections: systematic review and meta-analysis of individual participant data. BMJ 356:i6583. https://doi.org/10.1136/bmj.i6583

55. Nasser R, Naffaa ME, Mashiach T et al (2018) The association between serum magnesium levels and community-acquired pneumonia 30-day mortality. BMC Infect Dis 18:698. https://doi.org/ 10.1186/s12879-018-3627-2

56. Bhatt SP, Khandelwal P, Nanda S et al (2008) Serum magnesium is an independent predictor of frequent readmissions due to acute 
exacerbation of chronic obstructive pulmonary disease. Respir Med 102:999-1003. https://doi.org/10.1016/j.rmed.2008.02.010

57. Booth JV, Phillips-Bute B, McCants CB et al (2003) Low serum magnesium level predicts major adverse cardiac events after coronary artery bypass graft surgery. Am Heart J 145:1108-1113. https://doi.org/10.1016/S0002-8703(03)00077-2

58. Muller MP, Dresser L, Raboud J et al (2007) Adverse events associated with high-dose ribavirin: evidence from the Toronto outbreak of severe acute respiratory syndrome. Pharmacotherapy 27:494-503. https://doi.org/10.1592/phco.27.4.494

59. Mak IT, Chmielinska JJ, Spurney CF et al (2018) Combination ART-induced oxidative/nitrosative stress, neurogenic inflammation and cardiac dysfunction in HIV-1 transgenic (Tg) Rats: protection by Mg. Int J Mol Sci 19:2409. https://doi.org/10.3390/ ijms 19082409

60. Baby K, Maity S, Mehta CH et al (2020) Targeting SARS-CoV-2 RNA-dependent RNA polymerase: An in silico drug repurposing for COVID-19. F1000Research 9:1166. https://doi.org/10.12688/ f1000research.26359.1

61. Abdelaal A, Mahmoud M, Alkhatip A, Georgakis M, Montero VLR et al (2021) Metal-bound methisazone; novel drugs targeting prophylaxis and treatment of SARS-CoV-2, a molecular docking study. Int J Mol Sci 22:2977. https://doi.org/10.3390/ijms220629 77

62. Maier JA, Castiglioni S, Locatelli L et al (2020) Magnesium and inflammation: advances and perspectives. Semin Cell Dev Biol S1084-9521(20):30171-30173. https://doi.org/10.1016/j.semcdb. 2020.11.002

63. Brandao K, Deason-Towne F, Perraud A-L, Schmitz C (2013) The role of $\mathrm{Mg} 2+$ in immune cells. Immunol Res 55:261-269. https:// doi.org/10.1007/s12026-012-8371-x

64. Minton K (2013) Immunodeficiency: magnesium regulates antiviral immunity. Nat Rev Immunol 13:548-549. https://doi.org/10. 1038/nri3501

65. Hu B, Guo H, Zhou P, Shi Z-L (2021) Characteristics of SARSCoV-2 and COVID-19. Nat Rev Microbiol 19:141-154. https:// doi.org/10.1038/s41579-020-00459-7

66. Fan L, Zhu X, Zheng Y, et al. (2021) Magnesium treatment on methylation changes of transmembrane serine protease 2 (TMPRSS2). medRxiv 03.11.21253287

67. Errasfa M (2021) Magnesium therapeutic potential against Covid19: Could it be an "All-in-one" therapy? Magnes Res. https://doi. org/10.1684/mrh.2020.0474

68. Altura B (2016) Potential roles of magnesium deficiency in inflammation and atherogenesis: importance and cross-talk of platelet-activating factor and ceramide. J Clin Exp Cardiol 07:3-7. https://doi.org/10.4172/2155-9880.1000427

69. Detopoulou P, Demopoulos CA, Antonopoulou S (2021) Micronutrients, phytochemicals and mediterranean diet: a potential protective role against COVID-19 through modulation of paf actions and metabolism. Nutrients 13:462. https://doi.org/10.3390/nu130 20462

70. Demopoulos C, Antonopoulou S, Theoharides TC (2020) COVID19 , microthromboses, inflammation, and platelet activating factor. BioFactors 46:927-933. https://doi.org/10.1002/biof.1696

71. Akbar MR, Wibowo A, Pranata R, Setiabudiawan B (2021) Low Serum 25-hydroxyvitamin D (Vitamin D) level is associated with susceptibility to COVID-19, severity, and mortality: a systematic review and meta-analysis. Front Nutr 8:660420

72. Gommers LMM, Ederveen THA, van der Wijst J et al (2019) Low gut microbiota diversity and dietary magnesium intake are associated with the development of PPI-induced hypomagnesemia. FASEB J 33:11235-11246. https://doi.org/10.1096/fj.20190 0839R
73. Fan L, Yu D, Zhu X et al (2021) Magnesium and imidazole propionate. Clin Nutr ESPEN 41:436-438. https://doi.org/10.1016/j. clnesp.2020.12.011

74. Gasmi A, Tippairote T, Mujawdiya PK et al (2021) The microbiota-mediated dietary and nutritional interventions for COVID-19. Clin Immunol 226:108725. https://doi.org/10.1016/j.clim.2021. 108725

75. Kim HS (2021) Do an altered gut microbiota and an associated leaky gut affect COVID-19 severity? MBio 12:e03022-e3120. https://doi.org/10.1128/mBio.03022-20

76. Vignesh R, Swathirajan CR, Tun ZH et al (2020) Could perturbation of gut microbiota possibly exacerbate the severity of COVID19 via cytokine storm? Front Immunol 11:607734. https://doi.org/ 10.3389/fimmu.2020.607734

77. Zeng H-L, Yang Q, Yuan P et al (2021) Associations of essential and toxic metals/metalloids in whole blood with both disease severity and mortality in patients with COVID-19. FASEB J 35:e21392. https://doi.org/10.1096/fj.202002346RR

78. Alamdari NM, Afaghi S, Rahimi FS et al (2020) Mortality risk factors among hospitalized COVID-19 patients in a major referral center in Iran. Tohoku J Exp Med 252:73-84. https://doi.org/10. 1620/tjem.252.73

79. Quilliot D, Bonsack O, Jaussaud R, Mazur A (2020) Dysmagnesemia in Covid-19 cohort patients: prevalence and associated factors. Magnes Res 33:114-122. https://doi.org/10.1684/mrh.2021. 0476

80. Anuk AT, Polat N, Akdas S et al (2020) The relation between trace element status (Zinc, Copper, Magnesium) and clinical outcomes in COVID-19 infection during pregnancy. Biol Trace Elem Res. https://doi.org/10.1007/s12011-020-02496-y

81. Sarvazad H, Cahngaripour SH, Eskandari Roozbahani N, Izadi B (2020) Evaluation of electrolyte status of sodium, potassium and magnesium, and fasting blood sugar at the initial admission of individuals with COVID-19 without underlying disease in Golestan Hospital. Kermanshah New Microbes New Infect 38:100807. https://doi.org/10.1016/j.nmni.2020.100807

82. Al-Hakeim HK, Al-Jassas HK, Morris G, Maes M (2021) Increased angiotensin-converting enzyme 2, sRAGE and immune activation, but lowered calcium and magnesium in COVID-19: association with chest CT abnormalities and lowered peripheral oxygen saturation. medRxiv 2021.03.26.21254383

83. Alfano G, Ferrari A, Fontana F et al (2021) Hypokalemia in patients with COVID-19. Clin Exp Nephrol 25:401-409. https:// doi.org/10.1007/s10157-020-01996-4

84. Alnafiey MO, Alangari AM, Alarifi AM, Abushara A (2021) Persistent Hypokalemia post SARS-coV-2 infection, is it a life-long complication? Case report. Ann Med Surg 62:358-361

85. Tan CW, Ho LP, Kalimuddin S et al (2020) Cohort study to evaluate the effect of vitamin $\mathrm{D}$, magnesium, and vitamin $\mathrm{B}(12)$ in combination on progression to severe outcomes in older patients with coronavirus (COVID-19). Nutrition 79-80:111017. https:// doi.org/10.1016/j.nut.2020.111017

86. Pourdowlat G, Mousavinasab SR, Farzanegan B et al (2021) Evaluation of the efficacy and safety of inhaled magnesium sulphate in combination with standard treatment in patients with moderate or severe COVID-19: A structured summary of a study protocol for a randomised controlled trial. Trials 22:60

87. Ansu V, Papoutsakis C, Gletsu-Miller N et al (2021) Nutrition care practice patterns for patients with COVID-19-A preliminary report. JPEN J Parenter Enteral Nutr. https://doi.org/10.1002/jpen. 2106

88. Pulido Perez P, Póndigo de los Angeles JA, Hernández Hernández ME, et al (2021) Renal function, serum magnesium levels and mortality in COVID-19 patients with Type 2 Diabetes. Mgnesium Res (In press) 
89. Song E, Zhang C, Israelow B et al (2021) Neuroinvasion of SARSCoV-2 in human and mouse brain. J Exp Med 218:e20202135. https://doi.org/10.1084/jem.20202135

90. Song W-J, Hui CKM, Hull JH et al (2021) Confronting COVID19-associated cough and the post-COVID syndrome: role of viral neurotropism, neuroinflammation, and neuroimmune responses.
Lancet Respir Med S2213-2600(21):00125-00129. https://doi. org/10.1016/S2213-2600(21)00125-9

91. Zocchi M, Béchet D, Mazur A et al (2021) Magnesium influences membrane fusion during myogenesis by modulating oxidative stress in C2C12 myoblasts. Nutrients 13:1049. https://doi.org/10. 3390/nu13041049 